\title{
Case report: Fulminant pneumococcal sepsis in an unvaccinated asplenic patient in Italy
}

M Chironna () (1,2, A Sallustio ${ }^{1}$, A De Robertis ${ }^{1}$, M Quarto $^{1,2}$, C Germinario $^{1,2}$

1. Department of Biomedical Sciences and Human Oncology, Hygiene Section, University of Bari, Italy

2. Puglia Regional Epidemiological Observatory, Bari, Italy

Citation style for this article: Chironna M, Sallustio A, De Robertis A, Quarto M, Germinario C. Case report: Fulminant pneumococcal sepsis in an unvaccinated asplenic patient in Italy. Euro Surveill. 2010;15(23):pii=19585. Available online: http://www.eurosurveillance.org/ViewArticle.aspx?Articleld=19585

We report a fatal case of overwhelming pneumococcal infection in an asplenic young adult not vaccinated against Streptococcus pneumoniae (S. pneumoniae). Post-mortem microbiological investigations revealed the presence of $S$. pneumoniae in blood samples and lungs. Serotyping by molecular methods identified the presence of a $6 \mathrm{C}$ serotype not comprised in the current 23-valent pneumococcal vaccine, highlighting that a risk of fatal infections may persist even in vaccinated splenectomised individuals.

\section{Introduction}

Streptococcus pneumoniae (S. pneumoniae) is an important cause of upper respiratory tract infections and of severe invasive pneumoccoccal diseases (IPD) that include pneumonia, meningitis and sepsis [1].

To prevent pneumoccoccal diseases, two new polysaccharide-protein conjugate vaccines (PCV) are now available for vaccination of children, including infants. The 10-valent pneumococcal nontypeable Haemophilus influenzae protein D conjugate vaccine, Synflorix, approved by the European Medicines Agency (EMA), is used to prevent invasive pneumococcal disease and acute otitis media caused by pneumococcus, in infants and children [2]. The 13-valent PCV vaccine, Prevenar, containing six additional serotypes $(1,3,5,6 \mathrm{~A}, 7 \mathrm{~F}$ and $19 \mathrm{~A})$, has also been approved by EMA for use in children from six months to five years old [4].

The 23-valent pneumococcal polysaccharide vaccine (PPV23) has been designed for older children and adults at risk of pneumococcal disease [5].

Immunocompromised and asplenic patients are known to be particularly at risk for contracting overwhelming postsplenectomy infection (OPSI)[6] and should therefore be vaccinated to avoid serious illness and even death. Asplenic patients are strongly recommended to get vaccinated with PPV23, a one-dose vaccine, since they need protection against the maximum number of serotypes possible [5]. They are further recommended to repeat the PPV23 vaccination every five years due to the increased rate of decline of antibody levels observed in these subjects [7]. Long-term or emergency stand-by antibiotic prophylaxis is also recommended for asplenic patients because OPSI is a life-long risk for such individuals [8].

We describe a case of overwhelming pneumococcal disease with a fatal outcome.

\section{Case report}

A young male in his early thirties, with a history of post-traumatic splenectomy presented with symptoms of hyperpyrexia $\left(>41.5^{\circ} \mathrm{C}\right)$, nausea, vomiting and diarrhoea at the emergency department of our hospital. He was transferred to the intensive care unit the same day where he rapidly became dyspnoeic, developed cyanosis, tachypnea, went into shock and deteriorated continously. Despite ventilatory support, administration of intravenous fluids, antibiotics and vasopressor agents, the patient died a few hours following presentation. There was no history $S$. pneumoniae vaccination for the asplenic patient.

A chest X-ray taken upon admission demonstrated mild interstitial shadows; no apparent consolidation was observed in either lung. Because of the ongoing 2009 influenza $A\left(\mathrm{H}_{1} \mathrm{~N}_{1}\right)$ pandemic, real-time $P C R$ was performed to determine whether the patient was infected with the influenza $A\left(\mathrm{H}_{1} \mathrm{~N}_{1}\right)$ virus. The test yielded a negative result for influenza $A$ virus, including the pandemic $A\left(\mathrm{H}_{1} \mathrm{~N}_{1}\right)$ virus. Initial laboratory results revealed acidosis, marked leukopenia (2.0 x $103 \mu \mathrm{l}-1$ leukocytes), thrombocytopenia (6.0 x $103 \mu \mathrm{l}-1$ platelets) and considerably altered coagulation values consistent with the presence of disseminated intravascular coagulation. The coagulation values were out of measurable range.

Microbiological investigations on post-mortem biological samples revealed the presence of $S$. pneumoniae in blood samples and lungs. Serotyping of $S$. pneumoniae by molecular methods $[9,10]$ identified the presence of a 6C serotype.

\section{Discussion}

Fulminant, potential life-threatening infection due to S. pneumoniae is a major well-known risk after 
splenectomy. Strategies to prevent OPSI include immunisation, antibiotic prophylaxis and education. Several studies have shown the effectiveness of vaccination with PPV 23 in preventing IPD and recently it has been suggested that asplenic and hyposplenic individuals would benefit from vaccination against pneumococcae [11].

The serotype of $S$. pneumoniae strain isolated from the patient $(6 \mathrm{C})$ is not comprised in the current available 23 -valent pneumococcal vaccine. Pneumococcal vaccines contain serotype 6B and patients vaccinated with $\mathrm{PCV}_{7}$ and $\mathrm{PPV} 23$ show poor immune response against serotype $6 \mathrm{C}[12]$. Therefore, the patient may not have avoided IPD even after having been immunised. This highlights that a residual risk of contracting fatal infections may persist in splenectomised individuals even if vaccinated.

Various studies have provided conflicting evidence on the immune response to pneumococcal polysaccharide antigens in asplenic individuals $[13,14]$. A recent study did not provide evidence to recommend routine $\mathrm{PCV}_{7}$ immunisation over PPV23 immunisation in adult asplenic individuals [7]. In the future, higher valent pneumococcal conjugate vaccines should be tested in this group to better address this issue.

In Puglia, the PPV coverage among patients affected by a chronic disease is quite low and estimated to be about $20 \%$ [15]. Until further knowledge is gained regarding the protective concentration of serotypespecific antibody concentrations and the impact of PCV on adults, vaccination and regular revaccination, at least every five years, in combination with education of patients and healthcare professionals may be effective for patients at risk for OPSI. This case serves as a reminder that new immunisation strategies and practices should be implemented to also cover subjects at risk for OPSI and to increase PPV coverage. The goal should be to vaccinate at risk subjects through the National Health System, not only through general practitioners.

\section{References}

1. Centers for Disease Control and Prevention (CDC). Epidemiology and prevention of vaccine-preventable diseases. Atkinson W, Hamborsky J, Mclntyre L, Wolfe S, eds. 10th ed. 2nd printing. Washington, DC: Public Health Foundation; 2008. Available from: http://www.cdc.gov/vaccines/Pubs/pinkbook/ default.htm

2. Prymula R, Schuerman L. 10-valent pneumococcal nontypeable Haemophilus influenzae PD conjugate vaccine: Synflorix. Expert Rev Vaccines. 2009; 8(11):1479-500.

3. Centers for Disease Control and Prevention (CDC). Licensure of a 13-valent pneumococcal conjugate vaccine (PCV13) and recommendations for use among children-Advisory Committee on Immunization Practices (ACIP), 2010. MMWR Morb Mortal Wkly Rep. 2010; 59:258-61.

4. European Medicines Agency (EMEA) Doc. Ref.

EMEA/227936/2009 P/66/2009. Available from: http://www. ema.europa.eu/pdfs/human/paediatrics/000036-PIP0107-Mo2.pdf Accessed May 6, 2010.
5. Prevention of pneumococcal disease: recommendations of the Advisory Committee on Immunization Practices (ACIP). MMWR Recomm Rep. 1997; 46(RR-8):1-24. [No authors listed]

6. Lutwick LI. Infections in asplenic patients. 6th ed. Mandell GL, Bennett JE, Dolin R, editors. Principle and practice of infectious diseases. Pennsylvania: Elsevier Churchill Livingstone; 2005, 3524-32.

7. Stanford E, Print F, Falconer M, Lamden K, Ghebrehewet $\mathrm{S}$, Phin $\mathrm{N}$, et al. Immune response to pneumococcal conjugate vaccination in asplenic individuals. Hum Vaccin. 2009;5(2):85-91.

8. Davies JM, Barnes R, Milligan D; British Committee for Standards in Haematology. Working Party of the Haematology/ Oncology Task Force. Update of guidelines for the prevention and treatment of infection in patients with an absent or dysfunctional spleen. Clin Med. 2002; 2(5):440-3.

9. Pai R, Gertz RE, Beall B. Sequential multiplex PCR approach for determining capsular serotypes of Streptococcus pneumoniae isolates. J Clin Microbiol. 2006; 44(1):124-31.

10. Jin P, Xiao M, Kong F, Oftadeh S, Zhou F, Liu C, et al. Simple, accurate, serotype-specific PCR assay to differentiate Streptococcus pneumoniae serotypes 6A, 6B, and 6C. J Clin Microbiol. 2009; 47(8):2470-4.

11. Mourtzoukou EG, Pappas G, Peppas G, Falagas ME. Vaccination of asplenic or hyposplenic adults. Br J Surg. 2008; 95(3):273-80.

12. Park IH, Moore MR, Treanor JJ, Pelton SI, Pilishvili T, Beall B, et al. Differential effects of pneumococcal vaccines against serotypes 6A and 6C. J Infect Dis. 2008;198(12):1818-22.

13. Giebink GS, Foker JE, Kim Y, Schiffman G. Serum antibody and opsonic responses to vaccination with pneumococcal capsular polysaccharide in normal and splenectomised children. J Infect Dis. 1980;141(3):404-12.

14. Landgren O, Björkholm M, Konradsen HB, Söderqvist $M$, Nilsson B, Gustavsson A, et al. A prospective study on antibody response to repeated vaccinations with pneumococcal capsular polysaccharide in splenectomized individuals with special reference to Hodgkin's lymphoma. J Intern Med. 2004;255(6):664-73.

15. Martinelli D, Tafuri S, Caputi G, Fortunato F, Reggio P, Germinario C, et al. Eight years of active proposal of pneumococcal 23-valent polysaccharide vaccine: Survey on coverage rate among elderly and chronic patients. Am J Infect Control. 2010;38(4):e8-e15. 